\title{
Tsai Chiao: The founder of physiology and aviation, aerospace and navigation medicine in China
}

\author{
Yalan Wang ${ }^{1}$, Zijian $\mathrm{Li}^{2}$, Yanyan Qian ${ }^{2 \bowtie}$, Benyu Guo ${ }^{1}$ \\ ${ }^{1}$ Psychology College, Nanjing Normal University, Nanjing 210097, China \\ 2 Social and Behavioural Sciences Faculty, Leiden University, 2333 AK Leiden, Netherlands \\ $\bowtie$ Correspondence: psyqyy@163.com (Y. Qian)
}

On February 16th, 2019, Tsai Academician Museum held a launch ceremony of a minor planet (207681)'s settling in Jieyang County, Guangdong Province. This minor planet was given a new name Cai Qiao (Fig. 1) on October 14th, 2011. Cai Qiao was discovered at Xu Yi Station in the Purple Hills Observatory of the Chinese Academy of Sciences on August 16th, 2007. So who is the planet named after?

Tsai Chiao (蔡尧, 1897-1990) (Fig. 2) styled name was Zhuofu (卓夫), infant name was Yizhong (义忠). As one of the founders of Chinese physiology, Tsai promoted the development of Chinese physiology and also furthered the prosperity of international neuroanatomy. He was also the originator of China's aviation, aerospace and navigation medicine, who initially established China's aviation physiological system.

October 11th, 1897, Tsai was born in Xianmei Country, Xinheng Town, Jiedong Distinct, Jieyang City, Guangdong Province. Tsai went to an old-style private school when he was 7, and subsequently transferred to Lam Tin Government Elementary School. In 1913, he received education from Jinshan Academy located at Chaoan County, Guangdong Province, and graduated in 1917. In 1918, he received further education from Shanghai Fudan University Attached Middle School to improve his English. The same year, he became an external student of the Chinese Department of Peking University. In the autumn of 1919, deeply influenced by the cultural trend "Saving the Country through Science" of May 4th Movement, he went to America at his own expense.

Affected by behavioral psychologist Zing-Yang Kuo (郭任 远) (Qian et al., 2018), Tsai studied a regular college course for two years, firstly at Psychology Department, California University, and then transferred to the same department at Indiana University. In the winter of 1921, he entered the University of Columbia as a postgraduate. From 1922 to 1925, he transferred to the Department of Physiology, College of Arts and Sciences, University of Chicago to take more postgraduate courses. During this period, Professor Harvey A. Carr of comparative psychology supervised Tsai's study and Tsai majored mainly in psychology, minored in physiology and neuroanatomy. In 1924, Tsai gained a philosophic doctor degree with the doctoral thesis $A$ comparative study of retention curves for motor habits in which he further investigated the differences of memory retention between white rats and humans on a stylus maze problem (Tsai, 1924). In 1925, at the Hull Laboratory of Anatomy of Chicago University (Fig. 3), Tsai explored "the optic tracts and centers of the opossum (Tsai, 1925a)" and described its "descending tracts and related structures of the thalamus and midbrain (Tsai, 1925b)". In his exploration, Tsai described in great detail the ventral mesencephalic tegmentum where the nucleus pretectalis is located. This area is called Tsai's area or ventral area of Tsai. In addition, Tsai proved the fact that "the normal food-seeking impulse in the albino rat as measured by the choice method is stronger than that of sex (Tsai, 1925c)" against the Freudian conception that the sex urge is the strongest of all human motives. The same year Tsai was awarded Chicago University's Gold Key Award and recommended as a member of the American Association of Anatomists.

In the autumn of 1925, Tsai returned back to China. With the support of Zing-Yang Kuo, the vice-president of Fudan University, Tsai constructed biology discipline at Psychology College, Fudan University, taught biology and physiology, and cultivated a bunch of researchers like Yanfeng Hsü (徐 丰彦), Depei Feng (冯德培), Henian Chu (朱鹤年). In 1927, Tsai served as a Physiology Professor in the Medical Colleague of National Central University in Shanghai. Tsai acted as editor of the first textbook called Physiology, the first textbook of physiology in China, which was published in 1929 as part of a college book series. After that, Tsai also compiled 10 more Chinese physiology books including Physiology Experiment, Exercise Physiology and the 


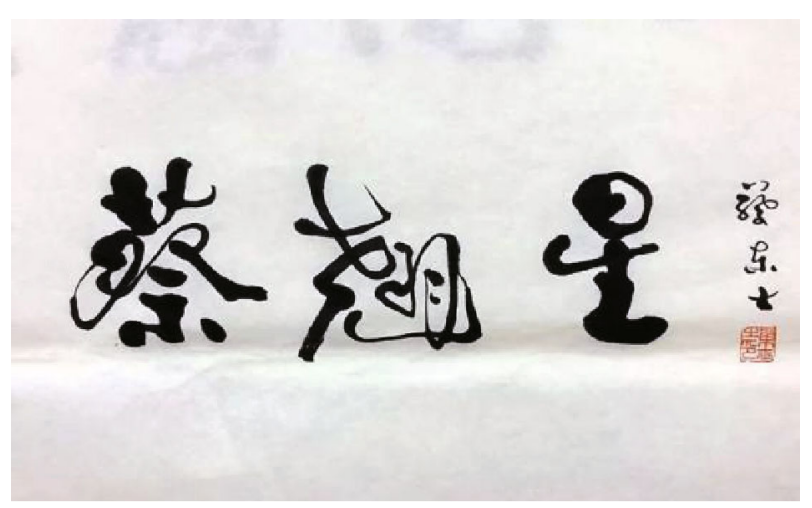

Figure 1. The name of minor planet Cai Qiao stem from Chinese physiologist Tsai Qiao.

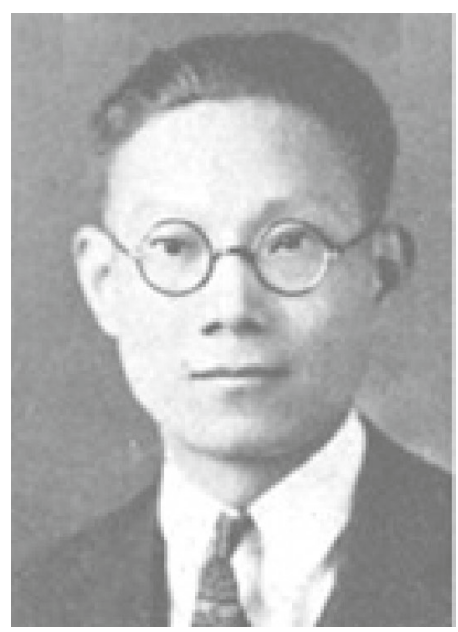

Figure 2. Tsai Chiao.

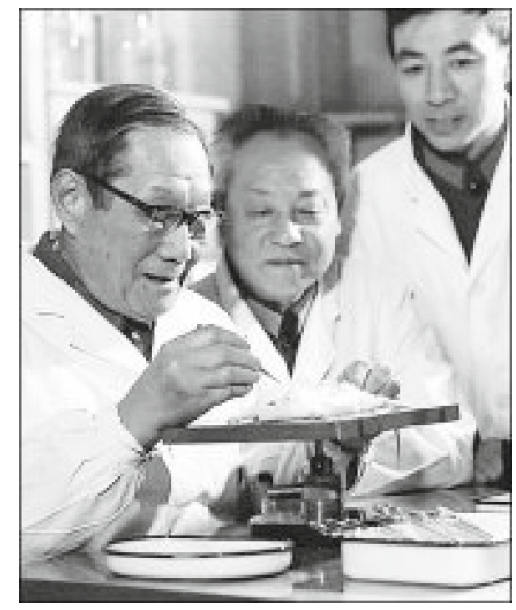

Figure 3. Tsai (first from the left) and the technicians were discovering the ventral mesencephalic tegmentum.
General Knowledge of Physiology. During this period, Tsai also published 8 papers concerning the issue of parathyroid. Firstly, co-operating with his teaching assistant Hsü, Tsai explored the relationship between parathyroid tetany and the removal of the large intestine (Tsai and Hsü, 1929a), ligation of the bile duct (Tsai and Hsü, 1929b), intestinal obstruction (Tsai and Hsü, 1929c) and intestine putrefaction (Tsai and Hsü, 1929d). Secondly, they studied plasma calcium and inorganic phosphorus following intravenous injections (Tsai and Hsü, 1930a; Tsai and Hsü, 1930b), and the calcium content of skeletal muscles after thyroparathyroidectomy and parathormone injections (Hsü and Tsai, 1930). Finally, he studied the effect of thyroparathyroidectomy and parathormone administration on the gastric motility in dogs (Tsai, 1930).

In the autumn of 1930, with funding from the Rockefeller Foundation, Tsai went to the Psychophysiology Laboratory in London. Under the supervision of Prof. C. L. Evans, he studied the changing situation of glycogen in cat livers under different conditions (Evans et al., 1931a, 1931b), as well as the action of adrenaline on glycogen distribution in the cat (Evans et al., 1931c). Afterwards, Tsai studied the action of narcotics on the conduction of nerve impulses from a single end-organ (Tsai, 1931) at E. D. Adrian's physiological laboratory, Cambridge University, the diagram of neuropotential of which cited by Starling's Principles of Human Physiology and Harris' Experimental Physiology.

In the winter of 1931, Tsai briefly visited Goethe University Frankfurt and the other famous physiological laboratories in Germany. From the spring of 1932 to the winter of 1936, Tsai was employed as a researcher in the field of physiology at the Henry Lester Institute of Medical Research, a Britishowned institution in Shanghai. During this period, he published 11 research articles in the Chinese Journal of Physiology from 1933 to 1937 . Tsai mainly studied the liver of animals. He explored the question of total carbohydrate content of the liver tissue in the fasting rabbit (Tsai, 1933a), and, with the cooperation of assistant Chien Lung Yi (易见 龙), taking the liver of the decapitated cat (Tsai, 1933b; Tsai and Yi, 1934a, 1934b, 1934c) and normal intact cat (Tsai and $\mathrm{Yi}, 1936 \mathrm{a}, \mathrm{b}$ ) as the research object, explored the role of the liver in carbohydrate metabolism on the premise of maintaining the normal blood glucose concentration, which were published in Volumes 8-10 of The Chinese Journal of Physiology. Then he explored the question of the validity of using aqueous extracts for estimating glycogen and total carbohydrate of the liver (Tsai, 1934). Based on the study of liver glycogen above, Tasi attempted to study the combined glycogen of liver and muscle (Tsai, 1937a; Tsai, 1937b). Finally, Tsai tried to improve angiostomy (Tsai, 1935). Finally, Tsai tried to improve angiostomy (Tsai, 1935).

In the autumn of 1936, Tsai waived his contract with the Henry Lester Institute of Medical Research one year ahead of schedule, and became a professor of physiology in the newly established Medical College of National Central University in Nanjing. Six months later, the July 7th incident 
happened, and Tsai moved to Chengdu together with the Medical Department of Central University. His contributions in Chengdu from 1937 to 1945 can be summarized as below: Firstly, Tsai manufactured experimental apparatus. He set up mechanical rooms in Medical Colleague, built equipment, such as soil lathes and drilling machines, which are a pivotal issue to physiological teaching and scientific research and purified pharmaceutical reagents for teaching and research. Secondly, he established academy. In the autumn of 1938, the Chengdu Branch of Chinese Association for Physiological Sciences was founded by Tsai and O. L. Kilborn, a physiology professor at West China Medical University. In the same year, Tsai organized the establishment of the institute of physiology to train trainees, among whom were secretly sent from the Yan'an Military Medical School, such as aeronautical physiologist Huishih Fang (方怀石). Thirdly, Tsai founded a journal to promote academic exchanges of the physiological science field among southwest China, domestic and overseas. Proceedings of Chinese Physiological Chengtu Branch started the publication work in June 1941, Tsai served as editor-in-chief, from then till June 1945, with 13 issues published in total. And this journal was the only physiological academic publication in the rear of AntiJapanese War. Finally, Tsai conducted blood research. Tsai, as the first author, participated in the academic writing of 11 papers, and guided students to publish more than 20 papers. Three themes were included in these papers: 1. Study on causes of increased erythrocytic fragility (Tsai et al., 1940, Tsai et al., 1941, 1942, Puh et al., 1945). 2. Study on haemolytic and antihaemolytic (Lee and Tsai, 1942a, Lee and Tsai, 1942b, Lee and Tsai, 1943). 3. Study on Chinese hematology standards (Wu and Tsai, 1940) and the standardization of Chinese people's sensory measurements (Wu and Tsai, 1943). In 1948, Gregerson, President of the American Bureau for Medical Aid to China, led professionals to China to hold a research class to teaching blood related technology. Having had the laboratory led by Tsai as a base, they organized the members of the research class to determine the blood coefficients of dozens of young Chinese.

In 1943, accompanied by another six professors which included Xiaotong Fei (费孝通), Tsai went to America with the identity of Exchange Professor for one year. Tsai introduced nutritional problems of China, with respect to the economic situation, agriculture development, healthy habits and education problems, towards American people (Liu et al., 1946). Also, he studied vasoconstrictor substances with two scholars in the Physiology Department, Medicine Colleague, Columbia University (Tsai et al., 1944), which promote the finding of 5-hydroxytryptamine (Zhang, 2013).

Tsai's earlier stage of academic work can be recognized from 1924 to 1948, whereby his research topic was foundation physiology. After 1948, his research turned to aviation physiology, navigation physiology with the need for national defense construction.
In 1948, Academia Sinica appraised and elected a total of 81 academicians, Tsai was one of 25 academicians in the biology group (Fig. 4). And appointed as the Dean of the medical superintendent of Nanjing University in 1949, principal of The Fifth Military Medical University in 1952, as a leader, he built the concrete human hypobaric chamber, which promoted the development of altitude hypoxia experiments (Zhang, 1997). From 1952 to 1954, Tsai guided young and middle age science and technology personnel and graduates to conduct psychological research including the topic of sleep and pilots' nutritional situation, which composed the first Summary of preliminary report on aviation physiology research.

Between 1954 and 1968, Tsai, on basis of the nomination from Central Military Commission, became vice-president of the Academy of Military Medical Sciences of PLA (Figs. 5 and 6) and director of Military Performance and Physiology Institute which was renamed the Aerospace Medicine

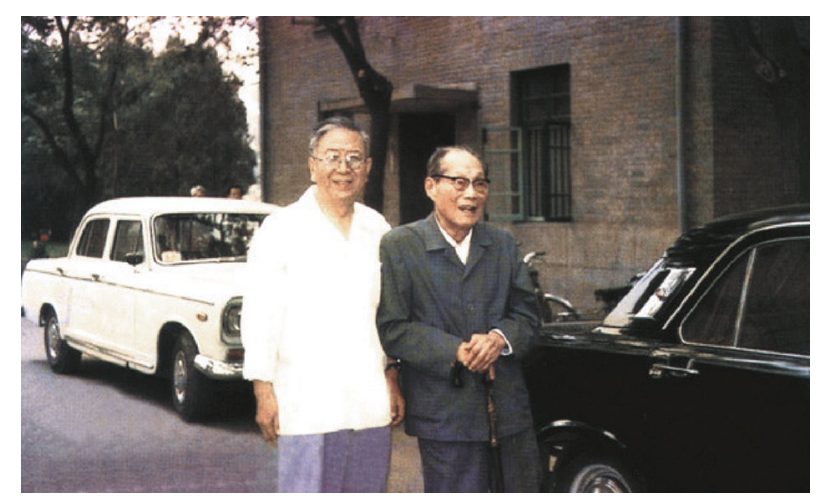

Figure 4. In 1986, Tsai (right) and Zhijun Wang, a physiologist, who was elected as academician in 1980 (Photo credit: Academician Library of Chinese Academy of Sciences https://yswk.las.ac.cn/).

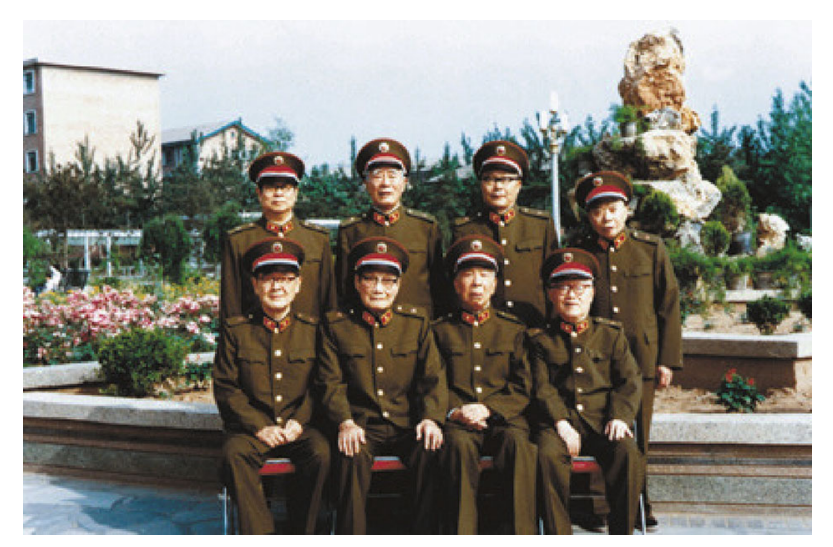

Figure 5. In 1985, Tsai (front row, second from left) and colleagues from the Academy of Military Medical Sciences of the Chinese People's Liberation Army (PLA) (Photo credit: Academician Library of Chinese Academy of Sciences https://yswk.las.ac.cn/). 


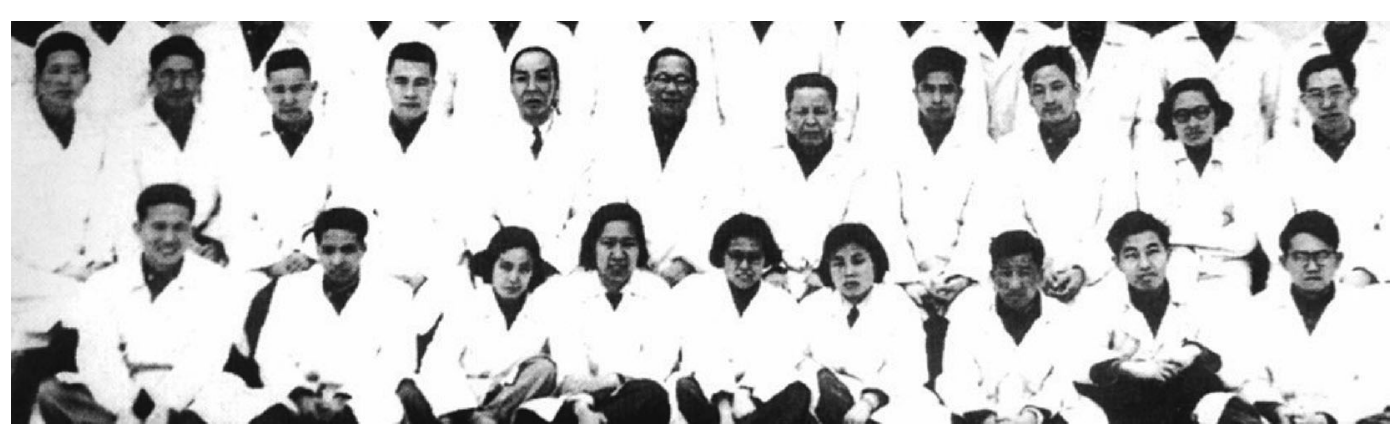

Figure 6. Group photo of teachers and students taken in the early day of the establishment of the Academy of Military Medical Science of PLA (Tsai is in the second row, sixth from the right) (Photo credit: Academician Library of Chinese Academy of Sciences https://yswk.las.ac.cn/).

Institute in 1964. Between 1957 and 1966, Tsai leaded people to build numerous large scale pieces of equipment and formulated safeguard regulations and device requests suitable for the Chinese Military. At the same time, Tsai took the role of vice-president of Academy of Military Medical Sciences of PLA, and leaded research to conduct scientific research related with aviation physiology. Then they wrote 12 papers for the Chinese People's Liberation Army Academy of Military Medical Sciences Proceedings, for example, with the theme of tentative modelling and identification of flight fatigue, the human body's tolerance of high and low temperature. Tsai also took part in the International Physiological Science, Brussels Conference in 1956. From August, 1956 to February, 1957, as the deputy head of the Chinese Military Medical Delegation, Tsai conducted an integrated survey in the Soviet Union for around six months (Figs. 7 and 8), then he participated in international conferences in Czechoslovakia and Poland. Tsai also attended the International Space Science Conferences in Warsaw, International

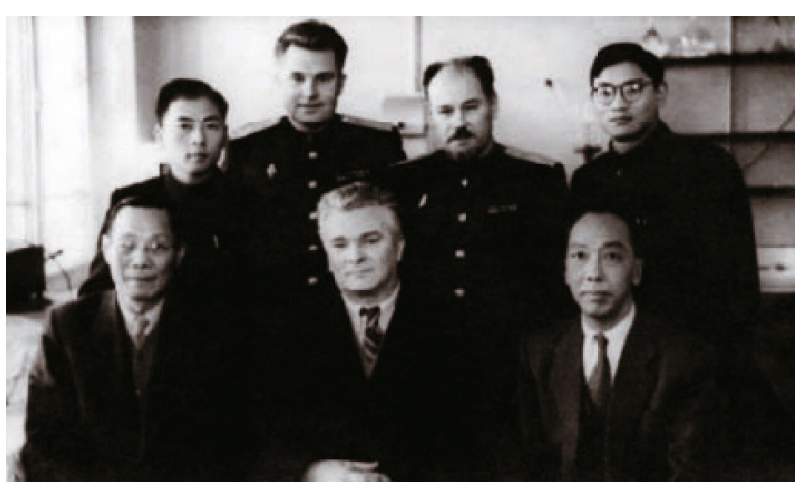

Figure 7. In 1956, Tsai (front row, first from the left) took a group photo with Soviet physiologists in the physiology department of the Kirov Academy of Military Medical Sciences in Leningrad, Soviet Union (Photo credit: Academician Library of Chinese Academy of Sciences https:// yswk.las.ac.cn/).
Aviation Space Medicine Conference in Ireland, and he also visited a research laboratory in London. In 1966, China made the cosmomedicine plan drafted by Tsai, and this led to the establishment of the Cosmomedicine Medical Engineering Institute, which contributed to the development of China's cosmomedicine career.

From 1966 to 1976, Tsai lost his medical career, but still insisted on writing Fundamentals of Aviation and Space Medicine, which was published in 1979. In 1978, Tsai reclaimed his title as vice-president at the Academy of Military Medical Science of PLA, where he guided research in the neurobiology laboratory and trained postgraduates (Fig. 9). In 1981, Tsai retired from the Chinese Association for Physiological Sciences with the position of president of a council. On July 29th, 1990, Tsai passed away.

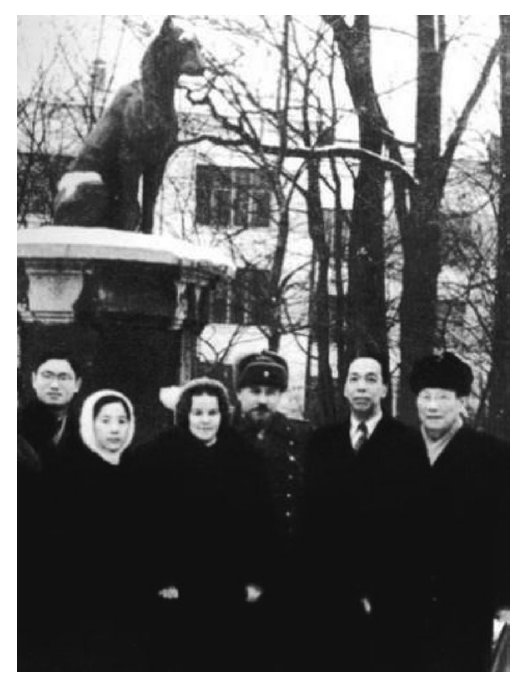

Figure 8. In 1956, Tsai (first from the right) visited the Soviet Union and took a photo in front of Leningrad Institute of Experimental Medicine (Photo credit:Academician Library of Chinese Academy of Sciences https://yswk.las.ac.cn/). 


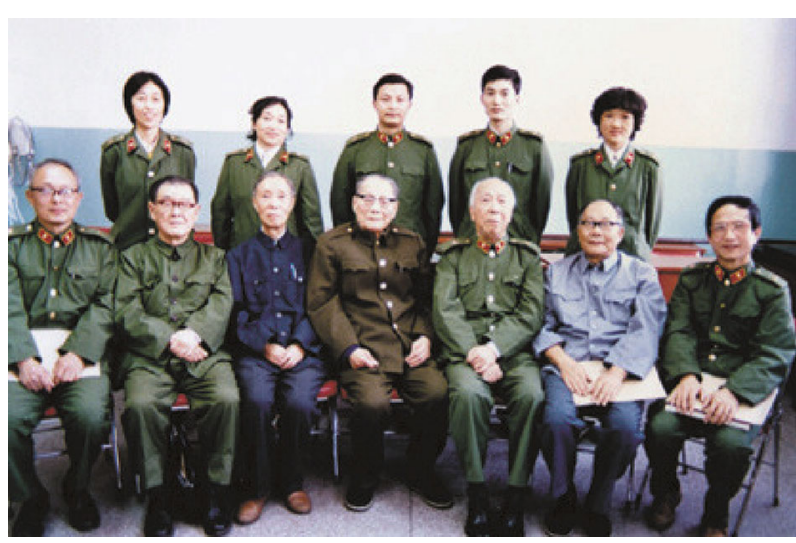

Figure 9. In September, 1986, Tsai (front row, in the middle), as the judge of doctoral thesis defense, took a photo with the jury and the Ph.D graduates after the defense meeting (Photo credit: Academician Library of Chinese Academy of Sciences https://yswk.las.ac.cn/).

\section{ACKNOWLEDGEMENTS}

The research of Yanyan Qian is supported by a post-graduate scholarship (PhD) of the China Scholarship Council (CSC).

\section{OPEN ACCESS}

This article is licensed under a Creative Commons Attribution 4.0 International License, which permits use, sharing, adaptation, distribution and reproduction in any medium or format, as long as you give appropriate credit to the original author(s) and the source, provide a link to the Creative Commons licence, and indicate if changes were made. The images or other third party material in this article are included in the article's Creative Commons licence, unless indicated otherwise in a credit line to the material. If material is not included in the article's Creative Commons licence and your intended use is not permitted by statutory regulation or exceeds the permitted use, you will need to obtain permission directly from the copyright holder. To view a copy of this licence, visit http:// creativecommons.org/licenses/by/4.0/.

\section{REFERENCES}

Chen TI,Tsai C (1948) The mechanism of haemostasis in peripheral vessels. J Physiol 107:280-288

Evans CL, Tsai C, Young FG (1931a) The behaviour of liver glycogen in experimental animals: I. Methods: the effect of ether and amytal. J Physiol 73(1):67-80

Evans CL, Tsai C, Young FG (1931b) The behaviour of liver glycogen in experimental animals: II. Glycogen recovery after decapitation and decerebration. J Physiol 73(1):81-102

Evans CL, Tsai C, Young FG (1931c) The action of adrenaline on glycogen distribution in the cat. J Physiol 73(1):103-114

Hsü FY, Tsai C (1930) A note on the calcium content of the skeletal muscles after thyroparathyroidectomy and parathormone injection. Chin J Physiol 4:423
Lee JS, Tsai C (1942a) Studies on the antihaemolytic properties of lecithin and cholesterol. Chin J Physiol 31:281-297

Lee JS, Tsai C (1942b) The protective action of serum against natural haemolysin. Physiol Soc Chengtu $\mathrm{Br}$ 1:44-48

Lee JS, Tsai C (1943) The development of a specific anticholesterol factor in the immune serum rum. Physiol Soc Chengtu $\mathrm{Br}$ 1:111120

Liu NC, Tsai C, Chu CK, MacNair HF (1946) Voice from unoccupied China. The University of Chicago Press, Chicago

Puh YC, Lee JS, Tsai C (1945) Blood platelet destruction as the main factor in increasing erythrocytic fragility during stasis. Physiol Soc Chengtu Br 11:149-155

Qian Y, Chen W, Guo B (2018) Zing-Yang Kuo and behavior epigenesis based on animal experiments. Protein Cell. https:// doi.org/10.1007/s13238-018-0516-9

Tsai C (1924) A comparative study of retention curves for motor habits. Comp Psychol Monogr 2(11):1-29

Tsai C (1925a) The optic tracts and centers of the opossum. Didelphis virginiana J Comp Neurol 39:173-216

Tsai C (1925b) The descending tracts of the thalamus and midbrain of the opossum, Didelphis virginiana. J Comp Neurol 39(2):217248

Tsai C (1925c) The relative strength of sex and hunger motives in the albino rat. J Comp Psychol 5(5):407-415

Tsai C, Hsü FY (1929a) Studies on the pathogenesis of parathyroid. I. The effect of removal of large intestine. Chin J Physiol 3:183196

Tsai C, Hsü FY (1929b) Studies on the pathogenesis of parathyroid tetany. II. The effect of ligation of the bile duct. Chin J Physiol 3:197-204

Tsai C, Hsü FY (1929c) Studies on the pathogenesis of parathyroid tetany. III. Influence of intestinal obstruction. Chin J Physiol 3:389-398

Tsai C, Hsü FY (1929d) Studies on the pathogenesis of parathyroid tetany. IV. Influence of intestine putrefaction. Chin J Physiol 3:399-404

Tsai C, Hsü FY (1930a) Plasma calcium and inorganic phosphorus following intravenous injection of parathyroid extraction: a study on the source of mobilized calcium. Chin J Physiol 4:265-272

Tsai C, Hsü FY (1930b) The effect of intravenous injection of sodium oxalate and citrate on the concentration of plasma calcium and inorganic phosphorous. Chin J Physiol 4:273-288

Tsai C (1930) The effect of thyroparathyroidectomy and parathormone administration on the gastric motility in dogs. Chin J Physiol $4: 415-422$

Tsai C (1931) Action of narcotics on the conduction of nerve impulses from a single end-organ. J Physiol 73(4):382-404

Tsai C (1933a) The total carbohydrate content of the liver tissue in the fasting rabbit: a method of estimation. Chin J Physiol 7:91102

Tsai C (1933b) Carbohydrate metabolism of the liver.l. Glycogen and other carbohydrates in decapitate cats. Chin J Physiol 7:215-228

Tsai C, Yi CL (1934a) Carbohydrate metabolism of the liver. II. The sugar output. Chin J Physiol 8:245-272

Tsai C, Yi CL (1934b) Carbohydrate metabolism of the liver. III. The sugar intake during glucose absorption. Chin J Physiol 8:273296 
Tsai C, Yi CL (1934c) Carbohydrate metabolism of the liver. IV. Sugar output in amytalized cats. Chin J Physiol 8:399-410

Tsai C, Yi CL (1936a) Carbohydrate metabolism of the liver. V. Sugar intake in the normal intact cat during glucose absorption. Chin J Physiol 10:87-104

Tsai C, Yi CL (1936b) Carbohydrate metabolism of the liver. VI. Sugar output and intake in the daily digestive cycle. Chin $\mathrm{J}$ Physiol 10:105-118

Tsai C (1934) The question of the validity of using aqueous extracts for estimating glycogen and total carbohydrate of the liver. Chin J Physiol 7:343-352

Tsai C (1937a) Studies on the combined glycogen of liver and muscle I Nature. Chin J Physiol 11:87-92

Tsai C (1937b) Studies on the combined glycogen of liver and muscle. II. Variation under different physiological conditions. Chin J Physiol 11:93-102

Tsai C (1935) An improved method of angiostomy. Chin J Physiol 9:355-362

Tsai C, Lee JS, Wu CH (1940) The role of splenic action in altering erythrocytic fragility. Chin J Physiol 15:165-180
Tsai C, Chen CJ, Chiu KY (1941) The relation of increased erythrocytic fragility induced by stasis to lactic acid content of the blood. Physiol Soc Chengtu $\mathrm{Br}$ 1:19-43

Tsai C, Chen CJ, Chiu KY (1942) Further observation on the various factors influencing the increase of erythrocytic fragility induced by stasis. Physiol Soc Chengtu $\mathrm{Br}$ 1:52-59

Tsai C, McBride JJ, Zucker MB (1944) An ether-extractable substance from blood serum and buffy coat which contracts smooth muscle. Proc Soc Exp Biol Med 55:283-285

Wu CH, Tsai C (1943) Standardization of some sensory measurements for Chinese. Physiol Soc Chengtu $\mathrm{Br}$ 1:130

Wu CH, Tsai C (1940) Hematological standards for the Chinese. Chin J Physiol 15(3):289-299

Zhang H (2013) Nanjing:The Biography of Science and Education Elites in the Republic of China. Nanjing Press. p. 289 [张衡 (2013) 民国科教精英百人传. 南京: 南京出版社. p. 289]

Zhang LF (1997) To commemorate the 100th anniversary of professor Tsai's birth. Chin J Aerosp Med 8(4): 196 [张立藩 (1997). 千秋风范照后人: 纪念蔡翘教授诞辰100周年. 中华航空航 天医学杂志, 196] 